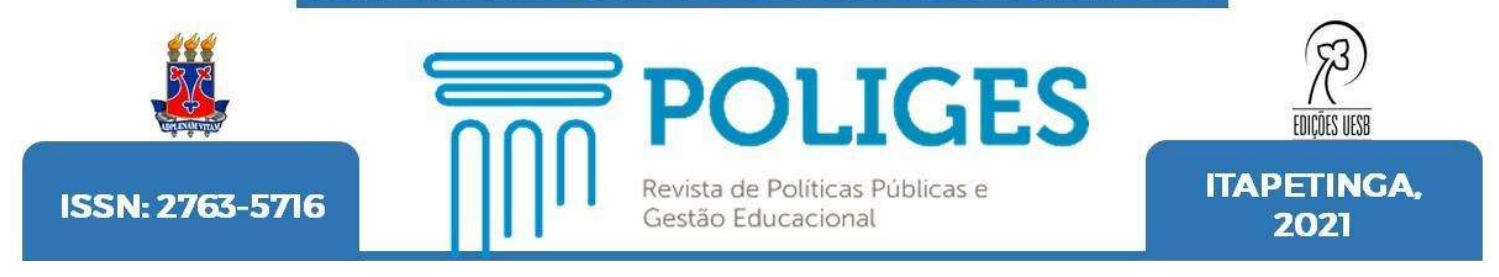

\title{
PLANEJAMENTO E GESTÃO: OS PLANOS DE EDUCAÇÃO NO BRASIL E A ORGANIZAÇÃO DAS POLÍTICAS EDUCACIONAIS
}

\author{
PLANNING AND MANAGEMENT: EDUCATION PLANS IN BRAZIL AND THE \\ ORGANIZATION OF EDUCATIONAL POLICIES
}

\section{PLANIFICACIÓN Y GESTIÓN: PLANES DE EDUCACIÓN EN BRASIL Y ORGANIZACIÓN DE POLÍTICAS EDUCATIVAS}

\begin{abstract}
Wilmara das Graças Pereira
ORCID iD: https://orcid.org/0000-0001-5682-30983805 Universidade Federal dos Vales do Jequitinhonha e Mucuri - UFVJM - Brasil

Mara Lúcia Ramalho

ORCID iD: https://orcid.org/0000-0002-8314-4688 Universidade Federal dos Vales do Jequitinhonha e Mucuri - UFVJM - Brasil
\end{abstract}

DOI: $10.22481 /$ poliges.v2i2.8736

\begin{abstract}
Resumo: O presente artigo tem por objetivo apresentar uma revisão bibliográfica de conceitos estruturantes necessários à compreensão dos elementos articuladores para a concretização do Plano Municipal de Educação - PME. O estudo ora apresentado é parte estruturante da dissertação de mestrado intitulada "Territórios da região metropolitana de Belo Horizonte: desafios desvelados nos planos municipais de educação" e que se encontra em andamento no Programa de Pós-Graduação em Educação- PPGED/UFVJM e, portanto, decorre de um estudo bibliográfico, considerado do ponto de vista metodológico, uma das etapas necessárias ao desenvolvimento da pesquisa documental, que orienta a organização da mencionada dissertação. As principais bases teóricas que sustentam este estudo estão pautadas em: Cury (1998), Saviani (2014), Romanelli (1996) e Azevedo (0000). Arcabouço este que instrumentaliza a compreensão acerca de importantes discussões, necessárias à compreensão do objeto de estudo em questão. Neste sentido, o estudo bibliográfico desvela um importante direcionamento que confirma a importância das políticas públicas educacionais para o planejamento e gestão municipal. Reforça ainda a relevância de um Plano Nacional de Educação com força de lei para a construção de um sistema articulado de ensino que dialogue com as demandas nacionais e regionais. Desvela ainda a importante função do PME como instrumento auxiliar no planejamento municipal. Por tal perspectiva, os Planos de Educação se configuram como uma ferramenta de gestão por uma perspectiva democrática.
\end{abstract}


Palavras-chave: Políticas Públicas educacionais. Plano Nacional de Educação. Plano Municipal de Educação

Abstract: This article aims to present a bibliographic review of structural concepts necessary to understand the articulating elements for the concretization of the Municipal Education Plan - PME. The study now presented is a structuring part of the master's thesis entitled "Territories of the metropolitan region of Belo Horizonte: challenges unveiled in the municipal education plans" and which is underway in the Graduate Program in Education - PPGED / UFVJM and, therefore, , stems from a bibliographic study, considered from the methodological point of view, one of the necessary steps for the development of documentary research, which guides the organization of the aforementioned dissertation. The main theoretical bases that support this study are based on: Cury (1998), Saviani (2014), Romanelli (1996) and Azevedo (0000). This framework instrumentalizes the understanding about important discussions, necessary to understand the object of study in question. In this sense, the bibliographic study reveals an important direction that confirms the importance of public educational policies for municipal planning and management. It also reinforces the relevance of a National Education Plan with the force of law for the construction of an articulated system of education that dialogs with national and regional demands. It also reveals the important role of the PME as an auxiliary instrument in municipal planning. From this perspective, Education Plans are configured as a management tool from a democratic perspective.

Keywords: Educational public policies. National Education Plan. Municipal Education Plan

Resumen: Este artículo tiene como objetivo presentar una revisión bibliográfica de conceptos estructurales necesarios para comprender los elementos articuladores para la concretización del Plan de Educación Municipal - PME. El estudio que ahora se presenta es parte estructurante de la tesis de maestría titulada "Territorios de la región metropolitana de Belo Horizonte: desafíos develados en los planes educativos municipales" y que se encuentra en marcha en el Programa de Posgrado en Educación - PPGED / UFVJM y, por tanto, surge de un estudio bibliográfico, considerado desde el punto de vista metodológico, uno de los pasos necesarios para el desarrollo de la investigación documental, que orienta la organización de la referida tesis. Las principales bases teóricas que sustentan este estudio se basan en: Cury (1998), Saviani (2014), Romanelli (1996) y Azevedo (0000). Este marco proporciona la comprensión sobre discusiones importantes, necesarias para comprender el objeto de estudio en cuestión. En este sentido, el estudio bibliográfico revela un rumbo importante que confirma la importancia de las políticas públicas educativas para la planificación y gestión municipal. También refuerza la relevancia de un Plan Nacional de Educación con fuerza de ley para la construcción de un sistema educativo articulado que dialoga con las demandas nacionales y regionales. También revela el importante papel del PME como instrumento auxiliar en la planificación municipal. Desde esta perspectiva, los Planes de Educación se configuran como una herramienta de gestión desde una perspectiva democrática.

Palabras clave: Políticas públicas educativas. Plan Nacional de Educación. Plan de Educación Municipal 


\section{Introdução}

O presente artigo é parte estruturante da dissertação de mestrado intitulada "Territórios da região metropolitana de Belo Horizonte: desafios desvelados nos planos municipais de educação", que se encontra em andamento no Programa de Pós-Graduação em Educação- PPGED/UFVJM. Tem como objetivo apresentar uma revisão bibliográfica de algumas discussões estruturantes para a compreensão dos elementos necessários à elaboração e monitoramento do Plano Municipal de Educação - PME.

O referido documento tem uma função normativa e contempla ações organizadas por meio de metas e estratégias propostas para a educação, a partir de um diagnóstico das demandas identificadas no município. É importante ressaltar ainda que o mencionado instrumento tem a sua elaboração vinculada ao atendimento dos pressupostos/metas da Lei $n^{\circ} 13.005$, de 25 de junho de 2014, que atribui força de lei ao atual Plano Nacional de Educação (PNE).

Tendo em vista o rigor científico, necessário ao desenvolvimento de uma pesquisa, buscar-se-á desenvolver o presente estudo, com a utilização de uma abordagem qualitativa e da realização de uma revisão de literatura, que é uma etapa do trabalho em que se reúne as fontes de pesquisa que vão fornecer embasamento teórico para a realização de um trabalho científico.

Assim, para Figueiredo (1990) a revisão de literatura, possui dois papéis interligados: o primeiro é que esta ação é parte integral do desenvolvimento da ciência e a função histórica e a segunda fornecem aos profissionais de qualquer área, informação sobre o desenvolvimento corrente da ciência e sua literatura: função de atualização.

Diante da importante discussão no cenário das políticas educacionais, após exposto, passar-se-á para a apresentação de algumas discussões necessárias a compreensão do objeto em estudo.

\subsection{Planos de Educação: uma ferramenta política, pedagógica e administrativa}


Tomar-se-á como primeiro ponto para a discussão a definição de plano, entendida por Aguilar (2001, p. 382) [...] " como formas de organizar toda estratégia governamental para dar cumprimento às políticas públicas que precisam ser implementadas. [...]

Para Cury (1998, p. 164), um plano pode ser considerado:

[...] um programa de realizações para ser cumprido e executado em um certo período (definição cronológica), dentro de objetivos a serem atingidos e para os quais se pleiteiam os meios, inclusive pecuniários, necessários para a implementação adequada.

Nessa perspectiva, o plano pode ser entendido como forma de organização de estratégias, com prazos determinados, sendo um projeto com etapas e ações para o alcance de objetivos estabelecidos.

Ao abordar o tema Planos de Educação, vale ressaltar que em abril do ano de 2007 foi apresentado ao país, o Plano de Desenvolvimento da Educação (PDE) como um programa federal, com o objetivo dos maiores investimentos na educação básica, educação profissional e ensino superior. Constituiu-se em um plano de governo que visava operacionalizar uma política de Estado, o PNE.

Segundo SAVIANI (2009) o PDE é constituído por ações que cobrem todas as áreas de atuação do MEC, abrangendo os níveis e modalidades de ensino, além de medidas de apoio e de infraestrutura. Por tal perspectiva, o PDE foi construído a partir de uma série de decisões expressas nos Decretos n 6.093 (dispõe sobre a reorganização do Programa Brasil Alfabetizado, com o intuito da universalização da alfabetização de jovens e adultos de quinze anos ou mais), n 6.094 (dispõe sobre a implementação do Plano de Metas Compromisso pela Educação, pela União Federal, em regime de colaboração com Municípios, Distrito Federal e Estados, e a participação das famílias e da comunidade).

Segundo HADDAD (2008) o PDE está sustentado em seis pilares: 1. Visão sistêmica da educação; 2. Territorialidade; 3 . Desenvolvimento; 4. Regime de colaboração; 5. Responsabilização; 6. Mobilização social; que são desdobramentos consequentes de princípios e objetivos constitucionais, com a finalidade de expressar o enlace necessário entre educação, território e desenvolvimento, de um lado, e o enlace entre qualidade, equidade e potencialidade, de outro. 
O mencionado Plano se fundamenta em uma perspectiva sistêmica, com pilares pautados no regime de colaboração, às normas gerais da educação na articulação com o desenvolvimento socioeconômico que se realiza no território, ordenado segundo a lógica do arranjo educativo - local, regional ou nacional (FERNANDES, 2013).

Nessa perspectiva, o PDE prevê várias ações que visam identificar e solucionar os problemas que afetam diretamente a educação brasileira, mas vai além por incluir ações de combate aos problemas sociais que inibem o ensino e o aprendizado com qualidade, como: luz para todos, saúde nas escolas e olhar Brasil, entre outros. As ações deveriam ser desenvolvidas conjuntamente pela União, estados e municípios.

Sendo assim, pode-se afirmar que o PDE se fundamenta uma concepção de educação alinhada aos objetivos constitucionalmente determinados à República Federativa do Brasil. Por tal motivo, esse alinhamento demanda uma ação por parte dos entes em prol a construção dos sistemas educacionais como sistema nacional que prime pela multiplicidade e não uniformidade.

Visto ser necessário considerar, nesse contexto, o enlace entre educação e a organização territorial, elemento essencial na medida em que é no território que as articulações culturais e sociais, dadas pela geografia e pela história, se manifestam, pois segundo Santos $(2001$, p.80):

O território não é um dado neutro nem um ator passivo. Produz-se uma verdadeira esquizofrenia, já que os lugares escolhidos acolhem e beneficiam os vetores da racionalidade dominante, mas também permitem a emergência de outras formas de vida. Essa esquizofrenia do território e do lugar tem um papel ativo na formação da consciência. O espaço geográfico não apenas revela o transcurso da história como indica a seus atores o modo de nela intervir de maneira consciente (SANTOS, 2001, p. 80).

Assim, o PDE, que se encontra no status de uma política pública educacional, toma no Brasil uma conotação que extrapola a mera tradução instrumental do Plano Nacional de Educação- PNE, Lei 13.000/2014, mas, em certa medida, apresenta um bom diagnóstico dos problemas educacionais e deixa em aberto a questão das ações a serem tomadas para a melhoria da qualidade da educação. No próximo tópico se apresenta uma breve contextualização sobre o Plano Nacional de 
Educação e os seus desdobramentos para a organização dos sistemas de ensino no Brasil.

\subsection{O Plano Nacional de Educação: o olhar para uma política pública no território Brasileiro}

O Brasil vivenciou a vigência de dois planos de educação com força de lei. $O$ primeiro Plano Nacional de educação - PNE, com força de lei, foi aprovado em 2001, por meio da Lei $N^{\circ} 10.172$, de 9 de janeiro de 2001. Para Didonet (2000), o PNE 2001-2010 entrou para a história da educação no Brasil distinguindo-se dos demais planos por seis qualificações básicas,

a) é o primeiro plano submetido à aprovação do Congresso Nacional, portanto, tem força de lei; b) cumpre um mandato constitucional (art. 214 da Constituição Federal de 1988) e uma determinação da Lei de Diretrizes e Bases da Educação Nacional (LDB, art. 87, $1^{\circ}$ ); c) fixa diretrizes, objetivos e metas para um período de dez anos, o que garante continuidade da política educacional e coerência nas prioridades durante uma década; d) contempla todos os níveis e modalidades de educação e os âmbitos da produção de aprendizagens, da gestão e financiamento e da avaliação; e) envolve o Poder Legislativo no acompanhamento de sua execução; e f) chama a sociedade para acompanhar e controlar a sua execução. (DIDONET, 2000, p. 11)

Após vigência do mencionado plano, o segundo com força de lei se legitima mediante a Lei № 13.005/2014 que se encontra em vigor até 2024. Assim, faz-se de fundamental importância a compreensão de que a conquista de um Plano que articula as demandas nacionais e as regionais e atribui de forma inédita o papel da instância governamental no planejamento, financiamento e desenvolvimento de ações que contribuam para a organização de um sistema articulado de ensino no Brasil, decorre de um processo cujos pilares estruturantes tem as suas bases em importantes aspectos, históricos, políticos, econômicos e pedagógicos. Neste tópico, optou-se por enfatizar com maior ênfase o processo histórico que direciona a organização dos planos de educação no Brasil.

De tal forma, pode-se afirmar que o PME no Brasil é fruto de um processo histórico, cujos pilares estruturantes se delineiam desde a década de 1930, em especial com a divulgação do Manifesto dos Pioneiros em 1932, momento em que 
se inicia a reconstrução de um projeto de educação, cujo eixo estruturante se organizou em torno da universalização da escola pública, laica e gratuita.

Muitos são os autores que dedicam esforços na reconstrução histórica do projeto de educação do Brasil, por meio dos marcos constitucionais e infraconstitucionais. No entanto, para que se tenha conhecimento sobre a organização dos movimentos e reformas em prol a reconstrução da educação nacional por meio da reconstrução de um projeto de educação, será importante retomar algumas discussões preconizadas por autores que se debruçam na análise criteriosa de tais aspectos, dentre eles: Cury (2009), Didonet (2000), Saviani (1998, 2009, 2014) e Romanelli (1986).

De acordo com Romanelli a Revolução de 1930 foi o ponto alto de uma série de revoluções e movimentos, que durante o período compreendido entre 1920 e 1964, se empenharam em promover vários rompimentos políticos e econômicos com a velha ordem social oligárquica. (ROMANELLI, 1986, p.47), o que justifica a opção neste tópico por tornar o período de 1930 como recorte para a discussão que se pretende realizar, visto não ser possível para a viabilidade científica do texto a adoção de um contexto de maior amplitude temporal.

Assim, diante a tal perspectiva, há mais de 80 anos, especificamente em 1932, destacados educadores e intelectuais brasileiros lançaram o Manifesto dos Pioneiros da Educação Nova, no qual recomendaram a necessidade da elaboração de um plano amplo e unitário para promover a reconstrução da educação no país. Segundo Saviani $(1988,75)$ a ideia de um plano em âmbito educacional remonta à década de 1930. "Provavelmente a sua primeira manifestação explícita nos é dada pelo Manifesto dos Pioneiros da Educação Nova lançado em 1932".

Tão forte foi esse alerta que, dois anos depois, a Constituição de 1934 incluiu um artigo que determinava como uma das competências da União, art. 150 Compete à União: a) fixar o plano nacional de educação, compreensivo do ensino de todos os graus e ramos, comuns e especializados; e coordenar e fiscalizar a sua execução, em todo o território do País; (CONSTITUIÇÃO FEDERAL,1934).

Durante o Estado Novo, o ministro da Educação, Gustavo Capanema, optou por reformas parciais traduzidas nas Leis Orgânicas de Ensino de 1942 em lugar de 
uma Lei Geral do Ensino, ou seja, do estabelecimento de um Plano Nacional de Educação como pretendiam os Pioneiros da Educação Nova.

Foi somente no governo de João Goulart (1956-1964) que tivemos mais desdobramentos específicos a respeito do PNE. Nesse período foi direcionado, por meio da lei $N^{\circ} 4.024$, de 20 de dezembro de 1961, a retomada da atribuição do Conselho Nacional de Educação - CNE em discutir e formatar o plano nacional de educação.

Um ano após, em 1962, surge a primeira proposta do PNE brasileiro, mas este documento assume naquele contexto um formato de conjunto de regras e ainda não daria conta de garantir uma contribuição para a reorganização de sistema de ensino, pois"[...] era basicamente um conjunto de metas quantitativas e qualitativas a serem alcançadas num prazo de oito anos. " (BRASIL, 2000, p.6).

Assim, o PNE no ano de 1964 foi modificado "[...] quando foram introduzidas normas descentralizadoras e estimuladoras da elaboração de planos estaduais" (BRASIL, 2000, p.6), regredindo, após apenas dois anos da sua implementação, de um plano nacional para vários planos regionais, tirando a responsabilidade federal, minimizando, com isso, os deveres financeiros da mesma.

Ainda em 1964, com a deposição de João Goulart pelas forças armadas, o Brasil entra no Regime Civil Militar marcado pela centralização do poder, extinção de partidos políticos, censura prévia dos meios de comunicação, afastamento das massas populares da participação política e adoção da tecnocracia nas instituições públicas.

Nesse contexto, diante das tendências tecnicistas e evidenciando melhor os desdobramentos das ações governamentais sobre o Plano Nacional de Educação, observa-se que,

em 1965, sofreu uma revisão, quando foram introduzidas normas descentralizadoras e estimuladoras da elaboração de planos estaduais. Em 1966, uma nova revisão, que se chamou Plano Complementar de Educação, introduziu importantes alterações na distribuição dos recursos federais, beneficiando a implantação de ginásios orientados para o trabalho e $\mathrm{o}$ atendimento de analfabetos com mais de dez anos. (BRASIL. LEI FEDERAL 10.172 de 2001).

Destacamos que entre os anos de 1964 a 1968, os presidentes militares: Humberto Alencar Castello Branco e Arthur da Costa e Silva junto aos americanos 
estabeleceram uma parceria, através do MEC, realizando doze acordos com a United States International for Development (USAID), realizado os acordos, fez com que esta parceria fosse tão significativa influenciando reformas e leis na área educacional brasileira.

Segundo Romanelli (1978), o agravamento da crise do sistema educacional, que já vinha de longa data, serviu como justificativa para os acordos entre MEC e a agência educacional dos Estados Unidos. Os conhecidos "Acordos MEC/USAID", eram firmados com a AID (Agency for International Development), a qual daria assistência técnica e financeira para o sistema educacional brasileiro.

No entanto, Cury (2009) ressalta que os diversos planos de desenvolvimento dos governos militares, entre os quais deveria constar o de Educação, não geraram benefícios substanciais para a educação brasileira. Isso pode ser exemplificado pelo fato de que a própria Constituição Federal promulgada em 1967 se por um lado amplia a obrigatoriedade de escolarização, por outro desvincula os recursos financeiros sustentadores da educação escolar.

No decorrer da década de 1980 a ditadura civil militar foi perdendo sua força, porém, deixando suas marcas em toda a sociedade, e também na educação. Dessa forma, mesmo após seu fim, a estrutura educacional mantinha uma identidade envolta diretamente com o setor econômico, o que a relacionava a uma dependência financeira internacional,

Nessas condições, não é difícil entender os constantes apelos para um maior estreitamento dos vínculos entre educação e mercado, a valorização da iniciativa privada com a consequente ênfase na adoção de mecanismos empresariais na gestão do ensino, assim como as pressões sobre a pós-graduação guiadas pela exigência de produtividade. (SAVIANI, 2008, p.311)

Além disso, apenas a partir de 1988 a determinação do Plano de Educação passa a ter o caráter constitucional prevalecendo, inclusive, sobre a LDB que anteriormente apontava diretrizes, mas não conferia aos Planos status de lei.

Os preceitos legais relativos ao estabelecimento de um PNE encontram-se postos tanto na Constituição Federal de 1988 quanto na Lei de Diretrizes e Bases da Educação Nacional n 9.394, de 20 de dezembro de 1996 com diretrizes e metas 
para os dez anos seguintes, em sintonia com a Declaração Mundial sobre Educação para Todos.

A Assembleia Nacional Constituinte, no calor da redemocratização e da intensa mobilização da sociedade pelo reordenamento jurídico do país e o estabelecimento de bases sólidas para a construção de uma sociedade livre, justa e democrática, acolheu a proposta de explicitar, na Constituição Federal, o dispositivo sobre o Plano Nacional de Educação de forma bem mais ampla do que nas Cartas Magnas anteriores. O art. 214 da nova Constituição expressa o desejo da nação brasileira de construir,

[...] um Plano Nacional de Educação, de duração plurianual, que leve à erradicação do analfabetismo, à universalização do atendimento escolar, à melhoria da qualidade do ensino, à formação para o trabalho e à promoção humanística, científica e tecnológica do País. (CONSTITUIÇÃO FEDERAL, 1988)

Ao se tomar como referencial a data da promulgação da Constituição Federal de 1988, pode-se afirmar que foram mais de oito até que, em 1996, com a aprovação da Lei de Diretrizes e Bases da Educação Nacional (Lei n 9.394/1996), fosse retomado o debate relativo à unificação de metas e objetivos para a educação nacional. Esta legislação reaproxima a lei do investimento educacional público, como também imprime ao momento a necessidade da elaboração do PNE.

Diante das demandas expressas para o contexto, em 09 de janeiro de 2001, foi aprovada a Lei 10.172, que instituiu o primeiro Plano Nacional de Educação com a vigência de dez anos. Cabe destacar a análise de Saviani (1998) que apresenta trecho da introdução do PNE, o qual:

menciona que o Plano Decenal de Educação para Todos como "o primeiro e mais importante subsídio ao PNE devendo, mesmo, constituir o cerne do novo documento a ser apresentado ao Congresso Nacional, em dezembro deste ano"(p.5); cita os compromissos assumidos pelo Brasil em nível internacional; considera as metas nacionais como médias propostas para todo o país podendo, assim, as metas estaduais ficar aquém ou além delas; apresenta um "roteiro-sugestão para Estados e Municípios cujos planos deverão incluir a descrição e análise da situação educacional, os obstáculos a serem enfrentados, os objetivos a serem atingidos e as estratégias de ação a serem implementadas; registra a importância do Conselho Nacional de Educação na elaboração do documento [...] (SAVIANI, 1998, p.82)

Ressalte-se que, em função da demanda pelo alcance de metas e estratégias a em prol a construção de um projeto nacional de educação em 2006, nasce um importante movimento na educação básica brasileira chamado "Todos pela 
educação". Esse movimento formado por uma organização da sociedade civil, sem fins lucrativos, plural, suprapartidária e independente foi fundado em setembro de 2006, momento em que ocorre a institucionalização do movimento por meio da carta Compromisso Todos Pela Educação.

De acordo com as informações do portal do MEC, no ano de 2007, a carta do Todos Pela Educação foi a base do Plano de Desenvolvimento da Educação (PDE) lançado pelo MEC. Seu maior indicador foi o Índice de Desenvolvimento da Educação Básica (IDEB). Diversas outras conquistas são destaques do movimento como: em 2009 ajudou a instituir a Emenda Constitucional (EC) $n^{\circ} 59$, que amplia a permanência na Educação Básica. Antes dela, a obrigação era dos 6 aos 14 anos; outra conquista através da EC 59 foi a redução gradual da desvinculação das receitas da União incidentes sobre a Educação.

Com base nas considerações, pode-se perceber que o PNE 2001-2011 definiu diagnósticos, diretrizes, objetivos e metas relacionadas aos níveis de ensino desde a Educação Infantil até o Ensino Médio, a educação superior e modalidades de ensino como a educação de jovens e adultos, dentre tantas colaborações para uma educação democrática e uma efetiva gestão com a colaboração dos entes federados.

Segundo Cury (2011) a elaboração de um Plano pressupõe um esforço consciente e contextualizado de metas cujo sucesso exige o conhecimento sistemático de limites, possibilidades e recursos. O autor ressalta assim a importância de um processo alinhado pelos governos nacional, estadual e municipal, ao qual o alinhamento das metas e estratégias seja oportuno para garantir um sistema de ensino efetivo.

O segundo Plano Nacional com força de lei encontra-se em vigência de 2014 até 2024, validado pela Lei 13.005 , de 25 de junho de 2014, e dá outras providências contando com 20 metas, em prazos estabelecidos. Além disso, esta Lei tem 254 estratégias relacionadas a essas metas e 14 artigos que definem ações a serem realizadas no Brasil.

É possível identificar como uma das limitações do atual PNE a ausência de diagnóstico do cenário educacional brasileiro, bem como o desvelamento dos 
processos avaliativos sobre o cumprimento das metas do PNE 2001- 2011. Para corroborar nesta análise nos apoiamos em Saviani (2014),

[...] mas a ausência do diagnóstico também torna o plano frágil. Isso porque o diagnóstico enquanto caracterização da situação com seus limites e carências, fornece a base da justificativa para o enunciado das metas que compõe o plano a ser executado. Sem ele, várias das metas resultam arbitrárias, não se entendendo, por exemplo, porque se pretende elevar taxa de alfabetização da população com 15 anos ou mais para $93,5 \%$ até 2015 [...] (SAVIANI, 2014, p.84).

Desse modo, partimos do entendimento de que é o diagnóstico que nos possibilita identificar o que temos, onde estamos em cada etapa e modalidade da educação básica ou do nível superior, e a situação do magistério, condições de trabalho e carreira dos profissionais da educação, bem como os investimentos.

Assim, para a realização de um processo de diagnóstico eficaz no âmbito nacional, se faz necessário obter as informações e os dados dos municípios e estados para se construir o planejamento futuro. No entanto, o que irá garantir esse planejamento serão o Plano Municipal de Educação dos municípios - PME, que permitirão a organização e materialização das ações futuras em busca de atingir as metas do PNE.

Sendo uma gestão centralizada, o processo de elaboração do PNE e sua materialização no formato de Planos Municipais de Educação (art. $8^{\circ}$ da Lei 13.005/2014) passam a ser uma nova política pública educacional necessária no Brasil.

Delega-se a ele, portanto, a responsabilidade de garantir que o sistema de ensino cumpra os dispositivos legais na garantia de acesso e permanência na escola, bem como em objetivos mais específicos que visem assegurar a qualidade da educação escolar. A estratégia 11 da meta 20 do PNE reforça esta afirmação:

[...] aprovar, no prazo de 1 (um) ano, Lei de Responsabilidade Educacional, assegurando padrão de qualidade na educação básica, em cada sistema e rede de ensino, aferida pelo processo de metas de qualidade aferidas por institutos oficiais de avaliação educacionais. (BRASIL, 2014)

O Plano Nacional de Educação trouxe mudanças quase que imediatas para a gestão municipal, uma vez que os municípios, de acordo com o art. $8^{\circ}$ da Lei 13.005/2014, deverão elaborar, no prazo de um ano, seu próprio Plano Municipal de Educação alinhando-o às metas dos Planos Nacional e Estadual de Educação.

Sabemos que a busca pela equidade e pela qualidade da educação em um país tão desigual como o Brasil é uma tarefa que implica políticas públicas 
de Estado que incluam uma ampla articulação entre os entes federativos. Vivemos atualmente um momento fecundo de possibilidades, com bases legais mais avançadas e com a mobilização estratégica dos setores públicos e de atores sociais importantes neste cenário. É possível realizar um bom trabalho de alinhamento dos planos de educação para fazermos deste próximo decênio um virtuoso marco no destino do nosso País. (MEC/SASE, 2014, p. 07).

Portanto, tendo como referência a Constituição Federal, a Lei de Diretrizes e Bases da Educação Nacional e o PNE estipulam que as metas nacionais, especialmente aquelas que dizem respeito às etapas obrigatórias da educação nacional são responsabilidades conjuntas da União, dos estados, do Distrito Federal e dos municípios.

Considerando que as visões de políticas públicas e as soluções para os desafios educacionais são as mais diversas e que os Planos Municipais de Educação elaborados ou adequados ao novo PNE e aos Planos Estaduais de Educação - PEE exigem compromisso e envolvimento de todos, faz-se necessário destacar os caminhos e construção dos PME.

\subsection{Os caminhos da construção do Plano Municipal de Educação}

Ao tratarmos a temática políticas públicas educacionais torna-se importante ressaltar o lugar da educação no âmbito da legislação nacional, em especial em três importantes documentos, a saber: a Constituição Federal de 1988, a Lei de Diretrizes e Bases da Educação Nacional - LDB, Lei 9.394/1996 e o Plano Nacional de Educação, Lei 13.005/2014, conforme se especifica, no primeiro deles.

Art. 205. A educação, direito de todos e dever do Estado e da família, será promovida e incentivada com a colaboração da sociedade, visando ao pleno desenvolvimento da pessoa, seu preparo para o exercício da cidadania e sua qualificação para o trabalho. (CONSTITUIÇÃO FEDERAL, 1988)

Assim, diante dos mencionados marcos infraconstitucionais destaca-se ainda o Plano Nacional de Educação, que se torna o ponto de partida para a discussão, por representar um grande avanço à educação nacional, estadual e municipal. Conforme menciona Cury (1998, p. 164):

(...)um plano supõe a clareza dos objetivos para se atingir metas prioritárias ou setoriais. Mas o que subjaz à finalidade de um plano como suposição é que a vida social pode ser ordenada, reordenada ou reconstruída pela ação racional do ser humano como ser social. 
Nesse sentido é que se enfatiza a importância de um país, em especial o Brasil, ter um Plano Nacional de Educação com força de lei, o qual permitirá que cada estado e município tenham objetivos a atingir na educação sem descurar, no entanto, de suas particularidades sociais.

Não se pode deixar de mencionar que tal documento, por meio do estabelecimento das metas, garante que os municípios possam desenvolver estratégias para o planejamento e gestão de políticas educacionais. Por essa tal perspectiva, constata-se que o PME é instrumento de planejamento que prima pela construção coletiva de um plano, cuja implementação dialoga com as demandas nacionais e regionais e, portanto, resguarda o potencial de mudar a forma como os gestores e a comunidade lidam com as políticas educacionais.

Diante do exposto, a importância da construção do PME se justifica pelos benefícios gerados pelo planejamento, ao possibilitar o exercício de uma gestão pautada no atendimento às demandas reais do município, que se articulam aos demais instrumentos de planejamento, viabilizando a execução financeira dos planos de educação, os quais terão de constar nos orçamentos da União e dos estados para que apoiem técnica e financeiramente os municípios ao longo do processo de desenvolvimento das ações.

Assim, a situação de planejamento proporcionada pelo PME possibilita aos governos municipais a realização de uma prática de diálogo entre os instrumentos necessários à ação de planejar: Plano Plurianual (PPA), Lei de Diretrizes Orçamentárias (LDO), Lei Orçamentária Anual (LOA), Plano de Ações Articuladas (PAR), dentre outros que forneçam elementos importantes ao reconhecimento das demandas em âmbito municipal.

Ao se consolidar o Plano Municipal de Educação, as instituições escolares precisam estabelecer um diálogo entre a concepção de planejamento e gestão educacional adotada em prol do desenvolvimento das ações, uma vez que é por meio deste mecanismo que as políticas educacionais se concretizam de fato no território, possibilitando melhorias na educação ofertada no município por meio do alcance das metas previstas no PME. 
Desse modo, entender o planejamento e a gestão educacional nos permite perceber os caminhos do processo de organização, bem como entender a elaboração do PME como uma situação de planejamento educacional e um importante instrumento auxiliar na consolidação das políticas públicas educacionais, com forte impacto na organização das práticas educativas dos sistemas de ensino. As principais referências para a vivência das ações planejadas visando o alcance das metas previstas no âmbito das políticas educacionais (CURY, 2009), em especial neste artigo, são o Plano Nacional de Educação - PME e o Plano Municipal de Educação - PME.

Ao considerarmos que os PME têm a função de possibilitar, por meio do diagnóstico do processo educacional, uma visão das demandas e desafios a serem atendidas e/ou superados pelo município, o trabalho com tal dimensão demanda a compreensão da territorialidade constituinte de tais localidades e, por meio das suas dimensões políticas, pedagógicas, econômicas, sociais e culturais, passem a dimensionar as ações a serem contempladas no planejamento.

Diante a tal constatação, faz-se mister explicitar que pensar em um território implica considerar que este conceito é alvo de diferentes definições e debates e, segundo Santos (1996), é construído não somente por suas fronteiras, uma vez que essas nem sempre são precisas ou visíveis, mas principalmente pelas relações simbólicas, estruturais e de poder que garantem a sua existência e dinamicidade.

(...) diante da realidade ao mesmo tempo global e local das redes, a tentação é grande de opor, desse ponto de vista, uma sociedade local a uma sociedade nacional, um território local ao território nacional e, mesmo uma formação socioeconômica local (ou regional) e uma formação socioeconômica nacional (SANTOS, 1996).

Fato este que se complementa nas discussões realizadas por Santos (1985) e Haesbaert (2004) que acrescentam a este conceito a possibilidade de uma dinâmica do território-rede, estabelecendo-se por diferentes pontos do espaço em áreas não necessariamente contínuas, mas com ligações e fluxos de informações que dialogam entre si. Em especial com o avanço da globalização e dos meios de transporte e comunicação, que fortalecem a existência de redes internacionais, interestaduais e intermunicipais entre territórios. Tais redes redundam em práticas de interação nas suas diferentes perspectivas: política, pedagógica, econômica e 
cultural, exercidas sobre certo comando ou domínio ou que interferem sobremaneira no planejamento que se realiza no município.

No entanto, diante das demandas pela compreensão dos instrumentos estruturantes para a realização de um planejamento que culmine na organização de um plano municipal, é que se apresentam algumas conceituações necessárias. Ao se dimensionar a organização de um plano é preciso considerar a existência de outras categorias, que se constituem em formas auxiliares no processo de gestão pública. Para além dos planos projetos e programas também podem ser utilizados.

A análise do cenário educacional no Brasil pressupõe a percepção que, ao longo da história, as concepções de planejamento vêm sendo modificadas de acordo com as demandas e conceitos estruturantes para cada contexto histórico. No âmbito do planejamento educacional, os planos municipais de educação surgem como instrumentos para que os municípios possam desenvolver suas políticas para a educação, por meio das metas e das estratégias definidas no documento.

Sendo assim, entendemos que são inerentes à prática do planejamento educacional atividades que busquem traçar um panorama da realidade educacional e que permitam sua elaboração mediante a prática da coletividade e da participação. Essas prerrogativas não são estranhas à construção de um Plano Municipal de Educação e são determinadas pelo Caderno de Orientações elaborado pelo próprio MEC, que assim diz:

O PME precisa estar alinhado ao PNE e ao PEE. Considerando que os Planos Municipais de Educação poderão ser limitados ou potencializados pelos Planos Estaduais, é recomendável que todos os segmentos da sociedade e das três esferas de governo se envolvam na construção dos PEE da mesma forma que se envolveram na construção do PNE e façam o mesmo com relação ao PME no seu respectivo município (BRASIL, 2014a, p. 7).

Recorrer à verificação do alinhamento entre metas estratégias e ações presentes nos PME, Plano de Ações e PNE, que facilitem a aplicação das políticas públicas educacionais será fundamental. Os referenciais para essa averiguação estão contidos na própria legislação brasileira: Lei 13.005/2014, LDBEN 9.394/1996 e a Constituição Federal de 1988. 
Cumpre registrar, para o efeito prático proposto pelo presente estudo, que os atuais Planos Estaduais e Municipais de Educação - PME são decorrências diretas da Lei 13.005/2014 que estabelece o PNE e preconiza em seu artigo $8^{\circ}$ que:

Os Estados, o Distrito Federal e os Municípios deverão elaborar seus correspondentes planos de educação, ou adequar os planos já aprovados em lei, em consonância com as diretrizes, metas e estratégias previstas neste PNE, no prazo de 1 (um) ano contado da publicação desta lei.

O processo de elaboração dos planos municipais mobilizou diferentes segmentos sociais e educacionais, o que pode ter sido construído de modo coletivo e participativo, uma vez que a CF de 1988 e a LDB de 1996 preconizam o princípio da gestão democrática na organização dos processos de gestão. Para Diniz (2015, p. 1) “os Planos não se constituem tão somente em uma exigência legal, são também uma reivindicação por parte de educadores e da sociedade, como forma de fazer um planejamento educacional em longo prazo". Desse modo, a elaboração dos PME favorece a superação das descontinuidades das políticas educacionais.

Após os estudos e diagnósticos realizados na elaboração, se faz necessário planejar a implementação do plano. De lá para cá, municípios e estados tiveram de ajustar seus planejamentos para torná-los mais efetivos com relação ao que foi definido no PNE.

O Plano Nacional de Educação e os Planos de educação do estado e do município devem formar um conjunto coerente, integrado e articulado para que os direitos dos cidadãos sejam garantidos e o Brasil tenha educação com qualidade para todos. Sendo o PME um documento criado para regularizar a educação ele é composto:

De estratégias e de políticas de educação que inclua a intenção de uma constante avaliação, à luz da Constituição Federal e Lei Orgânica do Município, observando os princípios estabelecidos na Lei das Diretrizes e Bases da Educação Nacional, interagindo com as metas definidas no Plano Nacional de Educação - Lei $n^{\circ} 10.172 / 2001$, e no Plano Estadual de Educação (BRASIL/MEC, 2005, p. 25).

Assim, o Plano Municipal de Educação ativo, oportuniza o Monitoramento contínuo e Avaliação periódica de seu desenvolvimento. Processo este que é realizado anualmente e a Avaliação de dois em dois anos, tanto um quanto o outro exige mobilização e ampla participação da comunidade escolar e sociedade civil por meio de Audiências Públicas e Conferências. 
Outra necessidade decorrente do plano decenal foi a definição de prioridades para cada ano da gestão, as chamadas metas intermediárias, que precisam ser constantemente revistas à luz das necessidades mais urgentes de cada localidade, dos prazos legais estabelecidos pelo PNE e da capacidade orçamentária.

Nesse contexto, é importante ressaltar que a construção dos Planos Municipais de Educação (PME) é um significativo exercício de conhecimento das realidades locais e de planejamento para os profissionais que atuam na educação pública. O momento de construção do plano possibilita o conhecimento da realidade local e o foco nos objetivos do plano.

Assim, a construção do PME deve estar em consonância com os Planos Nacional e Estadual de Educação, verificando as metas e as estratégias de cada plano. Segundo Bordignon (2009, p. 92):

O plano municipal de educação é o instrumento de gestão para tornar efetiva
a cidadania e a sociedade preconizada nas bases e diretrizes do Sistema
Municipal de Educação. Quando o município não tem plano fica à mercê de
ações episódicas que, mesmo planejadas caso a caso, representam
improvisações. Sem plano não há visão de Estado nas ações, não há
caminho a percorrer, mas apenas ao saber das circunstâncias de cada
Governo.
da maior importância que a Secretaria Municipal de Educação

É, portanto, da maior importância que a Secretaria Municipal de Educação auxilie as escolas e as diferentes instâncias a repensar a sua organização para atingir as metas e corresponsabilizar todos os profissionais, contribuindo para o fortalecimento da gestão democrática e a melhoria da qualidade da aprendizagem dos alunos.

Com certeza, a construção dos Planos Municipais de Educação representa avanços na política educacional brasileira, sendo assim, é de se esperar que os anseios e necessidades territoriais e/ou regionais se representem por meio do planejamento construído, a partir dos desafios locais. O Plano Nacional de Educação - PNE corrobora com o efetivo desenvolvimento dos PEE e PME, pois nestes se formarão a base principal para a efetiva realização do ideário proposto no plano nacional.

Dessa forma, o que se espera dos planos municipais é a articulação entre os entes federados e o reconhecimento das metas municipais, como ações que irão orientar as necessidades na área da educação de cada município, entretanto, será 
fundamental a parceria com as outras instâncias para que as propostas construídas entre união, estados e municípios sejam efetivamente alcançadas.

De acordo com orientações do Ministério da Educação, os Dirigentes Municipais de Ensino precisam superar a visão fragmentada de gestão da própria rede ou sistema de ensino. Para isso, é fundamental que se desenvolva uma concepção sistêmica de gestão no território e que se definam formas de operacionalização. (MEC/SASE, 2014).

As metas a serem cumpridas, que abrangem as diversas áreas da educação, com seus desafios em particular, como a universalização dos níveis de ensino, formação dos profissionais da educação, alfabetização, investimentos no setor, são temas bastante explícitos na proposta do documento. Ademais, a mesma moção faz menção às estratégias para se alcançar as metas originadas na lei.

Nesse sentido, é importante que as políticas públicas educacionais em suas diferentes instâncias: nacional, estadual e municipal tenham desenhadas em sua base a redução das desigualdades, com o direcionamento de mais e melhores estratégias educacionais justamente para as localidades e segmentos populacionais que mais precisam.

\section{Considerações finais}

Apresentam-se como constatações neste estudo três importantes direcionamentos. Em primeiro lugar pode-se mencionar a necessidade de uma abordagem da política educacional por meio dos planos de educação que contemple não apenas suas dimensões legais e constitucionais, mas enfatize também o planejamento, que pressupõe a realização de um diagnóstico e consequentemente viabiliza gerar um conjunto de ações da gestão pelo qual estas dimensões se articulam na definição e implementação da política pública e contemple as demandas do território o qual se destina

Em segundo lugar, o necessário resgate do movimento histórico pelo qual se configuram as dimensões necessárias à organização de um plano, em especial a dimensão ideológica que transversaliza todo o processo. Cabe salientar que o 
desafio colocado à gestão municipal para fazer acontecer as políticas educacionais, por meio de seus planos, vai além da análise das concepções e propostas apresentadas em seus programas. Requer também se valer de todo o processo histórico e político implícito a cada gestão em consonância com os seus contextos, que se relacionam com as convicções e ideologias dominantes no momento da organização dos planos.

E por fim um terceiro direcionamento, que desvela o exercício da política pública educacional por meio dos seus planos, como um avanço para além da evidência das limitações que estes colocam às práticas comprometidas com a transformação da sociedade e com os desafios impostos a cada município.

Após exposto, pode-se considerar que é importante que as pesquisas possibilitem compreender a relação dialética em que as diversas dimensões da realidade investigada atuam na configuração da política educacional.

Portanto, por meio deste artigo evidencia-se a importância das políticas públicas educacionais para o planejamento e para a gestão municipal, em especial a importância de um Plano Nacional de Educação com força de lei e do importante instrumento auxiliar no planejamento municipal os Planos de Educação, que se configura como uma ferramenta de gestão por uma perspectiva democrática.

\section{Referencias}

BRASIL. Constituição (1988). Constituição da República Federativa do Brasil: promulgada em 5 de outubro de 1988. Disponível em:

<http://www.planalto.gov.br/ccivil_03/constituicao/ConstituicaoCompilado.htm>. Acesso em: 12 out 2019.

BRASIL. Plano Nacional de Educação, 2000. Disponível em: <http://portal.mec.gov.br/arquivos/pdf/pne.pdf>. Acesso em: 17 jan. 2020. . Lei n. 9.394, de 20 de dezembro de 1996. Estabelece as Diretrizes e Bases da Educação Nacional. Brasília, DF, 23 dez. 1996. <http://www.planalto.gov.br/>. Acesso em: 14 out 2019.

. Lei n. 10.172, de 09 de janeiro de 2001. Aprova o Plano Nacional de Educação (PNE). Brasília, DF, 10 jan. 2001. <http://www.planalto.gov.br/>. Acesso em: 14 out 2019. 
. Lei n. 13.005, de 25 de junho de 2014. Aprova o Plano Nacional de Educação - PNE e dá outras providências. Brasília, DF, 26 jun. 2014. <http://www.planalto.gov.br/>. Acesso em: 14 out 2019.

BRASIL. Ministério da Educação / Secretaria de Articulação com os Sistemas de Ensino (MEC/SASE), O Plano Municipal de Educação: Caderno de Orientações. 2014.

BRASIL. Ministério da Educação. Secretaria de Educação Básica. Documento norteador para elaboração de Plano Municipal de Educação - PME / elaboração Clodoaldo José de Almeida Souza. - Brasília: Secretaria de Educação Básica. 2005. BRASIL.

HADDAD, Fernando. O Plano de Desenvolvimento da Educação: razões, princípios e programas / Fernando Haddad. - Brasília: Instituto Nacional de Estudos e Pesquisas Educacionais Anísio Teixeira, 2008.

BORDIGNON, Genuíno. Caminhar da educação brasileira: muitos planos, pouco planejamento. In: SOUZA, Donaldo Bello de; MARTINS, Ângela Maria (Org.).

Planos de educação no Brasil: planejamentos, políticas, práticas. São Paulo: Loyola, 2014. p. 29-54.

. Genuíno. Os Sistemas e os Conselhos de Educação. Revista Textual, outubro de 2008.

CURY, Carlos Roberto Jamil. A educação básica no Brasil. In: Educação e Sociedade, Campinas, vol. 23, n. 80, setembro/ 2008 (p. 169 a 201)

CURY, Carlos Roberto Jamil. Por um novo plano nacional de educação. Cad. Pesquisa, Dez 2011, vol.41, n.144, p.790-811. ISSN 0100-1574

DIDONET, Vital. Plano Nacional de Educação (PNE). Brasília, DF: Plano, 2000. . O Plano Nacional de Educação e os planos estaduais e municipais: uma conquista histórica. Gestão em Rede, Curitiba, n. 33, p. 14-19, nov./dez. 2001. 
FERNANDES, Thamyres Wan de Pol. Sistema Municipal de Educação de Juiz de Fora: as interfaces dos caminhos da cooperação e colaboração. 2013.195f.

Dissertação de Mestrado, Faculdade de Educação da UFJF. Juiz de Fora, 2013.

ROMANELLI, Otaíza de Oliveira. História da educação no Brasil. Petrópolis, Vozes, 1986

SANTOS, M. Território globalização e fragmentação. São Paulo: Hucitec,1994.

SAVIANI, Dermeval. O Plano de Desenvolvimento da Educação: análise do projeto do MEC. Educ. Soc., Out 2007, vol.28, no. 100, p.1231-1255.

SAVIANI, Dermeval. PDE - Plano de Desenvolvimento da Educação: Análise crítica da política do MEC. - Campinas, SP. Autores Associados, 2009.

SAVIANI, Dermeval. Organização da educação nacional: sistema e conselho nacional de educação, plano e fórum nacional de educação. Educ. Soc., Set 2010, vol.31, no. 112, p.769-787.

\section{SOBRE AS AUTORAS}

\section{Wilmara das Graças Pereira}

Mestranda em educação; Universidade Federal dos Vales do Jequitinhonha e Mucuri (UFVJM) - Brasil; Aluna do Programa de Pós-graduação (PPGED-UFVJM). wilmarapereira@yahoo.com.br.

\section{Mara Lúcia Ramalho}

Doutora em Educação pela Pontifícia Universidade Católica de Minas Gerais, PUC/MG (2016). Professora Adjunta da Universidade Federal dos Vales do Jequitinhonha e Mucuri UFVJM. Líder do grupo de Estudos e Pesquisas em Políticas, Práticas e formação dos profissionais da educação (GEPPRAFPE). mararamalho03@yahoo.com.br. 